\title{
Near future of Polish energy system - COP21 and BAT conclusions
}

\author{
Wojciech Suwała ${ }^{1, *}$, Artur Wyrwa ${ }^{1}$ and Marcin Pluta ${ }^{1}$ \\ ${ }^{1}$ AGH University of Science and Technology, Faculty of Energy and Fuels, Al. Mickiewicza 30, \\ 30-059 Krakow, Poland
}

\begin{abstract}
Next years will be very important for the development of the Polish energy system. Substantial part of the existing capacities are obsolete and need to be replaced or at least deeply modernised to fulfil expected emissions regulations. A hybrid of TIMES-PL and TIMESMACRO energy-economic models was used to analyse the possible changes in the power generation mix and economic impact of different scenarios that combine the climate and air pollution regulations. The results show that to maintain the $\mathrm{CO}_{2}$ emission reduction trend a combination of measures is needed including the use of renewables, nuclear, natural gas and clean coal technologies. However, such transition in the energy sector will lead to a cumulative GDP loss in the near future once the possible GDP gains could happen after 2045 in which the economic, technical and legislative conditions are very difficult to foresee.
\end{abstract}

\section{Introduction}

Next years will be very important for the development of the Polish energy system. There are problems inherited from the past. Due to insufficient investments in renewing the ageing generation assets during last two decades, nowadays the balancing of electricity demand becomes increasingly difficult, particularly during high demand periods. The constantly stiffening regulations on air pollution laid down by the EU Directives and Best Available Techniques (BAT) reference documents put burden on coal fired power plants, which dominate in the power generation mix. Another challenge is a reduction of GHG emissions in line with the Paris COP21 agreement and European Union declaration to decrease carbon dioxide emissions by $40 \%$ till 2030. One of EU instruments to reach such reduction is the EU Emission Trading System (ETS). In this system a limit on absolute amount of emissions from energy intensive industry, so called ETS sources (e.g. in power sector all generation units with total rated thermal input exceeding $20 \mathrm{MW}$ ) is set for a given period. At the same time the market of European Union Allowances (EUA) was established in which each emitter has to surrender sufficient number of EUAs to cover its emissions ( 1 EUA allows to emit 1 ton of $\mathrm{CO}_{2}$ ). Number of EUAs available in a given period corresponds to the emission cap and EUAs are to be purchased by ETS sources in

*Corresponding author: wojciech.suwala@agh.edu.pl 
auctioning system (for Polish electricity generators full auctioning will be obligatory after 2020). As a consequence of these climate and air pollution regulations a substantial part of existing obsolete capacities need to be replaced or at least deeply modernised. Taking into account that investments in the energy sector are irreversible all these aspects need careful consideration and discussion, involving decision makers, energy companies, experts and academics, in order to make the best possible transition of the energy system in near future. This discussion should be supported by the results of analytical tools, which are able to examine these diverse problems.

In this paper the hybrid of TIMES-PL and TIMES-MACRO energy-economic models was used to analyse the possible changes in the power generation mix and economic impact of different scenarios that combine the climate and air pollution regulations.

The paper starts with the discussion of circumstances and constraints forming scenarios of Polish energy system development, including time schedule of carbon dioxide emissions reduction and BAT conclusions. Nextly, the results of model calculations, mainly energy mix and costs of $\mathrm{CO}_{2}$ emission reduction are presented. Capacities of TIMES model make it possible to estimate the values of main variables determining and describing the operation of the energy system. This information help to reduce the uncertainties of system development planning and preparation of regulations. Finally, the main conclusions are drawn.

\section{Emissions and Regulations}

Conference of the Parties in Paris (COP21) set new rules in establishing climate policies. Instead of a top-down approach proposed in Kyoto Protocol in which emission reduction targets were assigned to countries accordingly to meet the global reduction target, according to the Paris Agreement Parties declare their intended nationally determined contributions (INDC) which they commit to fulfil. The United States and China, the world's biggest emitters of greenhouse gases agreed to ratify the Paris climate change agreement. US intends to achieve 26-28\% reduction below its 2005 level in 2025 whereas China aims at achieving peaking of its GHG emissions around 2030. The EU as a "bubble" has committed to a target of at least $40 \%$ domestic reduction in greenhouse gas emissions by 2030 compared to 1990 [1], but targets of individual Member States have not been declared. This declaration covers all greenhouse gases, and all sectors, i.e. these covered by the ETS but also others (non-ETS). In addition no international market based mechanisms will be included, but Land Use, Land Use Change and Forestry (LULUCF) contribution mechanism should be established before 2020 .

In face of this declaration the problem of intensity of GHG emissions reduction arises, especially for Poland which is considered as coal dependent.

The data on greenhouse gases emissions for EU28 and Poland (Fig. 1) indicate that for both cases continuation of past trends give in 2030 emissions above the $40 \%$ reduction target, excess is about 10\% and 5\% for EU28 and Poland respectively. But EU trend for the last ten years (EU10Y) indicates much higher intensity of reduction - about $100 \mathrm{Mt}$ per year, and continuation could give emissions $20 \%$ below the target.

The European Commission intends to reduce GHG emissions by $43 \%$ to 2030 comparing 2005 in ETS sector and 30\% in non-ETS sectors [2]. Individual countries' targets of total reduction within non-ETS sectors has been established at a range from $40 \%$ (Luxembourg) to $0 \%$ (Bulgaria), for Poland this is $7 \%$. 


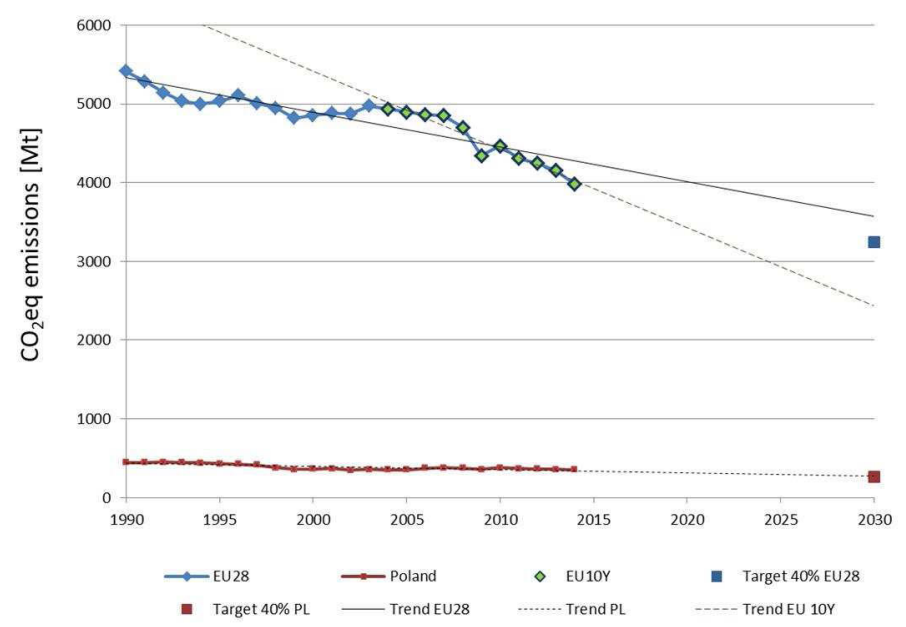

Fig. 1. GHG emissions in EU28 and Poland, trends and targets for 2030 (million metric tons). Source: own based on EUROSTAT data on greenhouse gas emissions by source sector

In case of Poland this target could be reached providing past trends will be continued (Fig. 2).

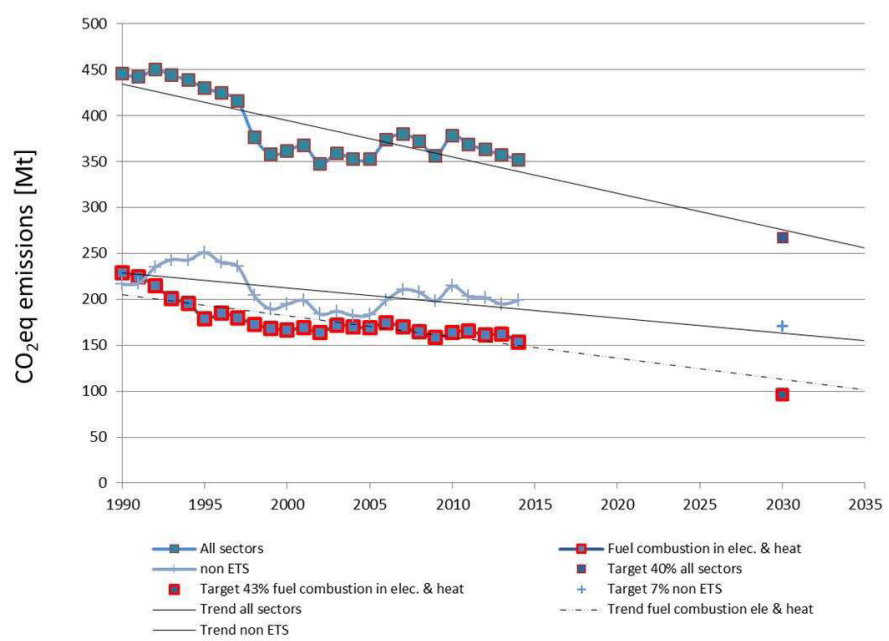

Fig. 2. GHG emissions in Poland, trends and targets for 2030 (million metric tons).

Source: own based on EUROSTAT data on greenhouse gas emissions by source sector

For traditional air pollutants the emission standards for the power plants are determined in some documents, mainly the following directives:

- LCP - Large Combustion Plants Directive,

- MCP - Medium Combustion Plants Directive [3] referring generally to plants or their combination with a total rated thermal input equal to or greater than $1 \mathrm{MW}$ and less than $50 \mathrm{MW}$,

- IED Industrial Emissions Directive,

- BAT new (conlucions) on attainable emissions standards, to be released in beginning 2017 and in force since 2021. 
These documents limit the power station emissions of main pollutants such as sulphur and nitrogen oxides, particulates (dust). New BAT regulations introduce limits on mercury as well as a new factor i.e. the efficiency of transformation processes.

Table 1. Examples of emission limit values ( $\mathrm{mg} / \mathrm{Nm} 3)$ for large combustion plants.

\begin{tabular}{|c|c|c|c|c|c|c|c|c|c|c|c|c|}
\hline \multirow[b]{2}{*}{ Year } & \multicolumn{4}{|c|}{ Dust - particulates } & \multicolumn{4}{|c|}{$\mathrm{SO}_{2}$} & \multicolumn{4}{|c|}{$\mathbf{N O}_{\mathrm{x}}$} \\
\hline & $\underset{్}{0}$ & 国 & $\begin{array}{l}.00 \\
.00 \\
0 \\
0 \\
0 \\
0\end{array}$ & 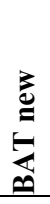 & $\underset{త}{\tilde{U}}$ & 氠 & $\begin{array}{l}.00 \\
.00 \\
0 \\
0 \\
0 \\
0\end{array}$ & 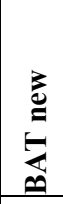 & 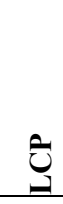 & 国 & 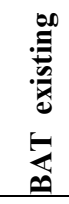 & 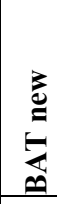 \\
\hline 2008 & 100 & & & & 1200 & & & & 600 & & & \\
\hline 2016 & 100 & 20 & & & 1200 & 200 & & & 600 & 200 & & \\
\hline 2021 & & 20 & 10 & $2^{*}$ & & 200 & 130 & $10^{*}$ & & 200 & 180 & $65^{*}$ \\
\hline 2030 & & & 10 & $2^{*}$ & & & 130 & $10^{*}$ & & & 180 & $65^{*}$ \\
\hline
\end{tabular}

Sources: $[4,5,6]^{*}$ The lower end of the range presented in [6].

The differences of allowed limits are impressive, especially for sulphur dioxide, for which limit is lowered by 120 times, however the restricted values are based of best available techniques analyses, thus attainable at rational cost.

\section{Objective of the study}

As presented in Fig. $2 \mathrm{CO}_{2}$ emissions from fuel combustion in public electricity and heat production have revealed the downward trend in the last two decades. The aim of the study was to (i) analyse possible future emission levels, (ii) estimate the $\mathrm{CO}_{2}$ abatement potential within this sector for different EUA price scenarios and (iii) assess the impact of these scenarios as well as the expenditures that are necessary to adopt the generation units to BAT requirements on Gross Domestic Product.

\section{Methodology}

The analysis of possible future emissions for different energy mix and EUA prices was done with the use of TIMES-PL. TIMES-PL belongs to a family of bottom-up, partial equilibrium models developed with the use of IEA-ETSAP TIMES generator [7]. Analysis of the development of Polish energy system under various energy and environmental constraints with the use of TIMES-PL has been presented in the following papers [8-11]. The electricity supply side in TIMES-PL is reflected at the unit generation level or its homogenous representations, with individual technical and economic characteristics, including learning processes outcomes $[10,11]$. The latest plans for decommissioning of existing capacities as well as for new investments are considered. New technologies such as Integrated Gasification Combined Cycle (IGCC) or small modular reactors are also considered and prospects of their deployment are evaluated. Additional data important for setting the optimal plan are prices of fuels, and demand for electricity and heat. The latter is derived based on econometric methods mainly considering the rate of economy development. The model indicates optimal capacity expansion plan and depicts the operation on generation units. The time horizon taken into consideration in the current 
analysis covers the period between 2011 and 2050. Each modelled year is split into 224 time slices. This approach allows to consider the temporal characteristics of supply and demand side especially behaviour of intermittent renewable technologies is taken into account in higher resolution. The marginal $\mathrm{CO}_{2}$ emission abatement cost curve (MACC) has been built based on the results of consecutive TIMES-PL model runs with different EUAs prices. The first run started with the certificate price equal to $0 \mathrm{PLN} / \mathrm{tCO}_{2}$ and in each subsequent run the price has been increased by $25 \mathrm{PLN} / \mathrm{tCO}_{2}$ to finally reach 300 $\mathrm{PLN} / \mathrm{tCO}_{2}$. In each modelling year the abated $\mathrm{CO}_{2}$ emissions (i.e. difference in emission level) resulting from an increase in the $\mathrm{CO}_{2}$ certificate price were used to draw the abatement curve. Finally, the economic impact was assessed with the TIMES-MACRO model, which is also the results of the on-going IEA ETSAP project and aims at providing opportunity to analyse economic results of different policies. TIMES-PL and TIMESMACRO have been coupled (Fig. 3) to allow estimation of changes in GDP level as results of BAT requirements introduction as well as of various levels of EUAs prices.

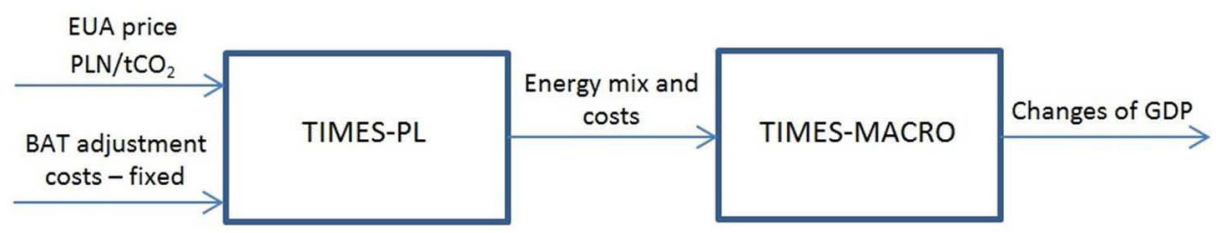

Fig. 3. The idea of the approach applied to estimate the economic results of different policies.

It should be noted, that the cost calculation of introduction of BAT conclusions is difficult without detailed data on possible emission controls that can be installed on each generation unit. Therefore the overall total costs of 10 Billion PLN were assumed as representing adjustment expenses, allowing estimation of impact on energy prices. The estimates of these costs, depending on scope and time distribution, range from 4 to 12 Billion PLN [12]. Therefore, the assumed amount is indicated as rational and in the line with the current policy oriented on ensuring energy security conditions.

\section{Scenarios considered}

The elements that form the scenario come from the main factors that will shape Polish energy system in the near future. These are mainly related to: (i) the EU and global climate policies resulting from COP21 agreement, and (ii) the restrictions on air pollutants' emissions which are expected to be determined based on the BAT conclusions [6]. Thus the following scenarios were formed:

- REF (reference) scenario based on the present regulations for emissions of traditional air pollutants and zero costs of carbon dioxide emissions allowances,

- BAT scenario assuming introduction of BAT conclusions, in which the costs necessary for modernisation and adjustments of generation assets to the BAT conclusions requirements were taken into account, based on the mentioned study [12],

- Different EUA price scenarios, in which the carbon price ranged from 150 to 300 $\mathrm{PLN} / \mathrm{tCO}_{2}$, as a measure of undertaken less/more ambitious EU policy targets to reduce carbon dioxide emissions in ETS sector, it is assumed that the technologies fulfil BAT requirements. 


\section{Results}

One of the most informative tools for the GHG abatement policies evaluation are the aforementioned MACCs. Fig. 4 presents the emissions reduction that occurs for various levels of EUA price. This stepwise curve illustrates capacities of reduction, which as explained later, come from possibilities of replacing cheap but highly carbon intensive coalbased power generation with generation from other technologies. For instance, total $\mathrm{CO}_{2}$ reduction potential as referred to the REF scenario in 2030 is nearly $100 \mathrm{Mt}$ annually. This is about $2 / 3$ of the present $\mathrm{CO}_{2}$ emission level from fuel combustion for electricity and heat production. Such reduction could be achieved at high EUA price reaching $300 \mathrm{PLN} / \mathrm{tCO}_{2}$ (approximately $70 € / \mathrm{tCO}_{2}$ ). Recent forecasts of EUA values [2] are lower; the $70 € / \mathrm{tCO}_{2}$ level is reached in 2045 linearly from present low values.

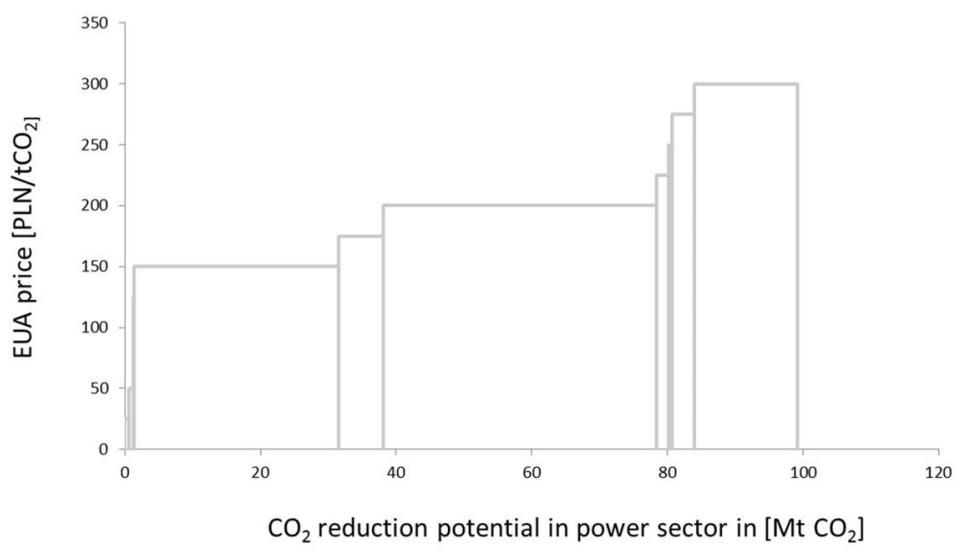

Fig. 4. Abatement cost curve for power sector in Poland for 2030 generated with the TIMES-PL model.

The details of technological changes to reach the emission reduction depicted in Fig. 4 are illustrated in Fig. 5. One can see that up to 2030 there is practically no change in electricity generation mix as compared to the REF scenario unless the price of EAU certificate exceeds $150 \mathrm{PLN} / \mathrm{tCO}_{2}$. Above this price firstly the power generation in most inefficient hard coal fired power plants and CHPs is replaced with nuclear- and natural gasbased generation. The higher the EAU price the more natural gas is used but also new hard coal units equipped with CCS are built (although the future application of CCS in power sector is often questioned [10] in the current study the assumption has been made that CCS would be available starting from 2030). The stable generation from gas CHPs is the result of limited heat demand. Due to construction time constraint also limited generation is observed from new nuclear units. 


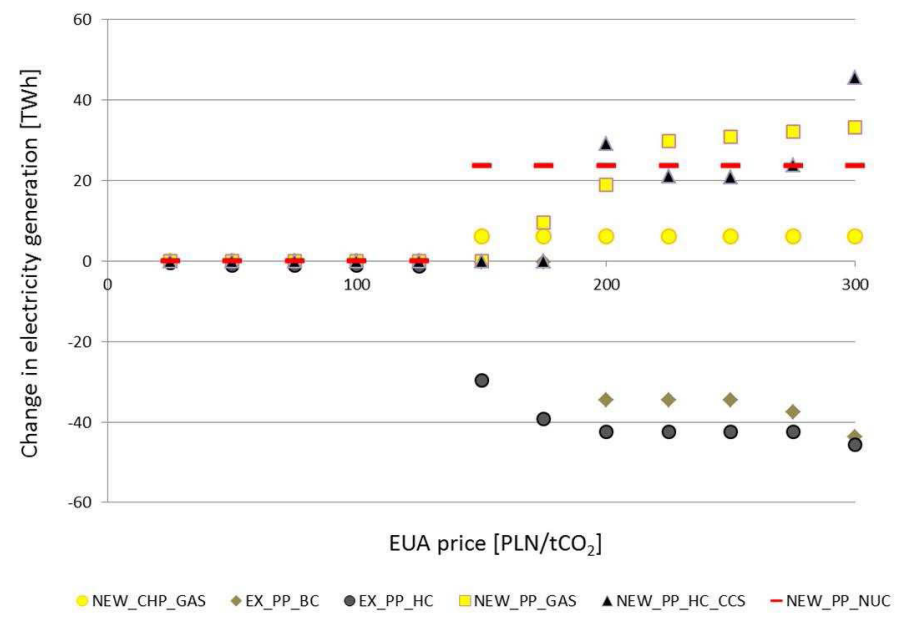

Fig. 5. Change in net electricity generation in 2030 as a result of EUA price change in relation to the Reference scenario $\left(0 \mathrm{PLN} / \mathrm{tCO}_{2}\right)$ in most impacted power technologies.

The decreasing trend in $\mathrm{CO}_{2}$ emissions with the increase in power demand is to be maintained till 2030 with the EAU certificate price around $150 \mathrm{PLN} / \mathrm{tCO}_{2}$ (Fig. 6). This is mainly possible due to introduction of nuclear power generation and increase of gas use mainly in CHP units. One should note, that this EAU price is slightly lower that the current wholesale electricity price (average $180 \mathrm{PLN} / \mathrm{MWh}$ in 2015).

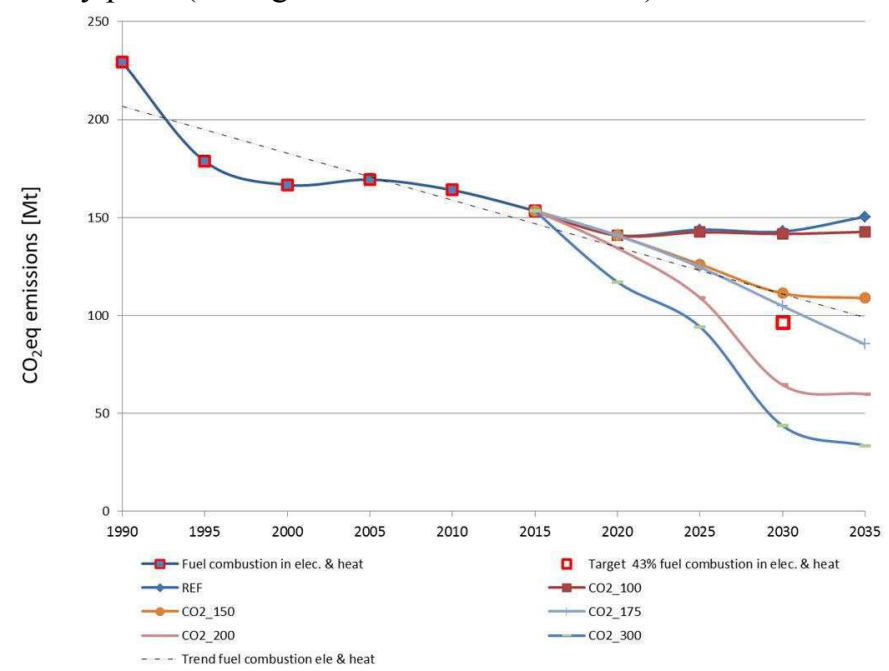

Fig. 6. Historical and estimated $\mathrm{CO}_{2}$ emissions for different EUA price scenarios.

Data presented in Fig. 6 indicate that the EUA price of $175 \mathrm{PLN} / \mathrm{tCO}_{2}$ (approximately $40 € / \mathrm{tCO}_{2}$ ) will lead the sector to the required level of emissions reduction after 2030. The electricity generation mix for different EUA price is presented in Fig. 7. 

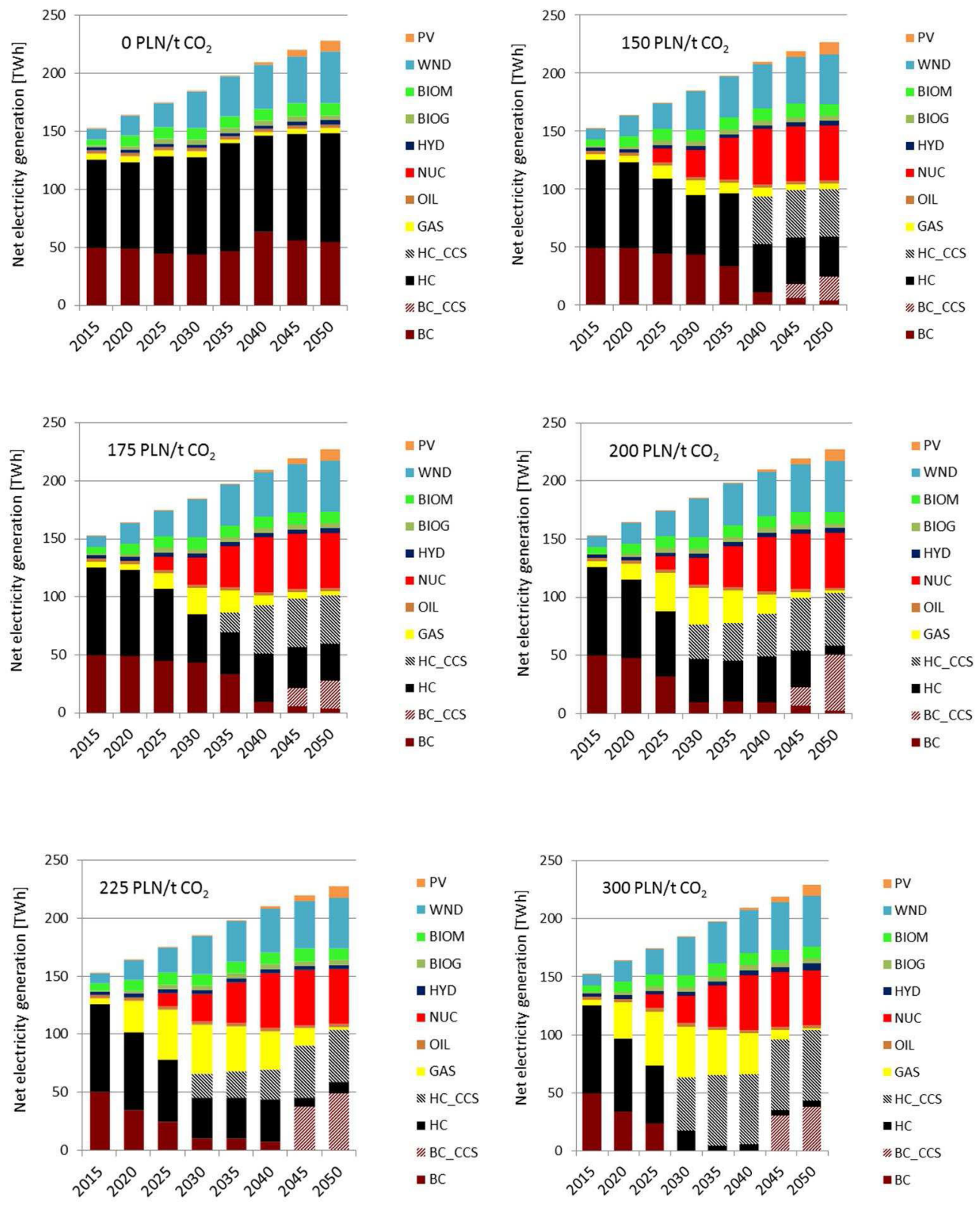

Fig. 7. Electricity generation mix for different EUA price. 
Finally, the results of the impact of the energy scenarios on GDP are presented in Fig. 8. This figure presents the relative change in GDP compared to the REF scenario as the result of transitions of the energy system. One can see that in the mid-term adjusting of the power sector to the climate and air pollution regulations will result in a relative GDP loss in all scenarios. The increasing trend in the GDP loss is reversed due to lower energy costs and investments: (i) around 2030 for the BAT scenario and around (ii) 2040 for the other ones. In fact, in the case of first scenario group we can observe a GDP gains in the long term i.e. around 2050. Also for other two scenarios we see the rapid decline in GDP loss and if this trend was continued one could expect to have GDP gains before 2060. However, one should note that the cumulative GDP loss would not be compensated in any of these scenarios within the modelling time horizon.

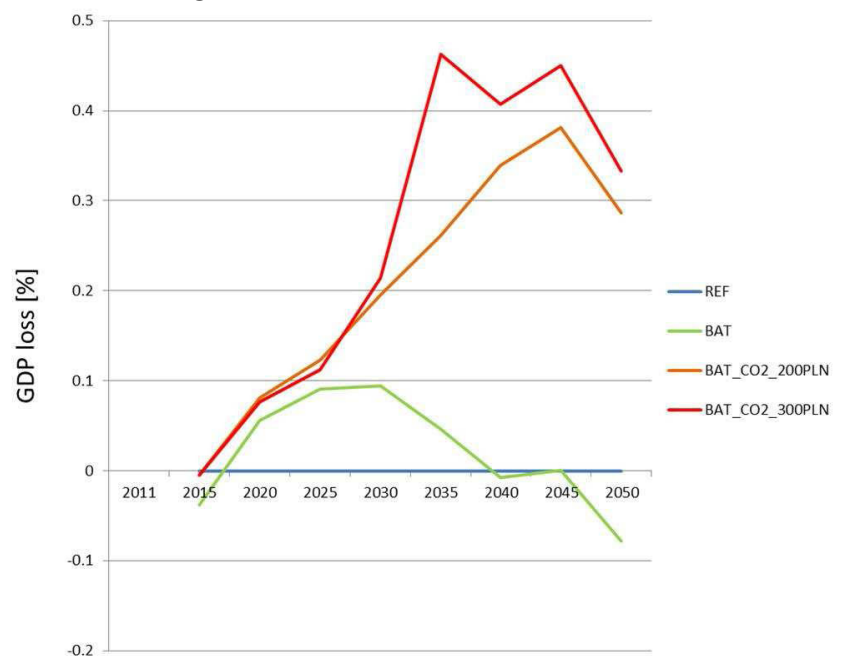

Fig. 8. The relative value of GDP loss for different energy scenarios referred to the REF scenario.

\section{Conclusions}

In this paper a hybrid of TIMES-PL and TIMES-MACRO energy-economic models was used to analyse the possible changes in the power generation mix and economic impact of different scenarios that combine the climate and air pollution regulations. The first observation is that the potential of renewable energy sources is fully exploited in all the scenarios even without stimulation of phasing out the intensive $\mathrm{CO}_{2}$ generation (Fig. 7). This notwithstanding, still big $\mathrm{CO}_{2}$ reduction potential exist in replacing inefficient hard coal fired power plants and CHPs with nuclear- and natural gas-based generation. Also clean-coal CCS technologies revealed to be competitive. In a short term i.e. till 2030 no significant change to the power mix could happen without very high EUA price signal. At the same time the study shows that cumulative GDP loss due to high EAUs prices and BAT-related expenditures would not be compensated within the modelling time horizon 2011-2050 in any of the scenarios considered. Moreover, the GDP loss will happen in the near future once the possible GDP gains could happen after 2045 in which the economic, technical and legislative conditions are very difficult to foresee. 


\section{References}

1. Intended Nationally Determined Contribution of the EU and its Member States, Submission by Latvia And The European Commission On Behalf Of The European Union and its Member States Riga, 6 March 2015 http://www4.unfccc.int/Submissions/INDC/Published\%20Documents/Latvia/1/LV-0306-EU\%20INDC.pdf (access 15.07.2016)

2. EU Reference Scenario 2016 Energy, transport and GHG emissions Trends to 2050, European Commission Directorate-General for Energy, Directorate-General for Climate Action and Directorate-General for Mobility and Transport, (July 2016)

3. DIRECTIVE (EU) 2015/2193 OF THE EUROPEAN PARLIAMENT AND OF THE COUNCIL of 25 November 2015 on the limitation of emissions of certain pollutants into the air from medium combustion plants

4. DIRECTIVE 2001/80/EC OF THE EUROPEAN PARLIAMENT AND OF THE COUNCIL of 23 October 2001 on the limitation of emissions of certain pollutants into the air from large combustion plants

5. DIRECTIVE 2010/75/EU OF THE EUROPEAN PARLIAMENT AND OF THE COUNCIL of 24 November 2010 on industrial emissions (integrated pollution prevention and control)

6. Best Available Techniques (BAT) Reference Document for Large Combustion Plants Industrial Emissions Directive 2010/75/EU (Integrated Pollution Prevention and Control) Joint Research Centre Institute for Prospective Technological Studies Sustainable Production and Consumption Unit European IPPC Bureau Final Draft (June 2016)

7. R. Loulou, U. Remme, A. Kanudia, A. Lehtila, G. Goldstein, Documentation for the TIMES Model - Part I, ETSAP, (2005)

8. M. Pluta, A. Wyrwa, T. Mirowski, J. Zyśk, Wyniki wstępnych badań nad dtugookresowym rozwojem krajowego systemu wytwarzania energii elektrycznej $w$ Polsce - Results of preliminary studies on the long-term development of the power system in Poland, Polityka Energetyczna: ISSN 1429-6675, t. 15 z. 4, s. 85-96, (2012), (in Polish)

9. A. Wyrwa, M. Pluta, J. Zyśk, Modeling the mid-term development of the energy system in Poland with the use of TIMES-PL model, ENERDAY conference on energy economics and technology: energy policies and market design in Europe, Dresden, (2013)

10. L. Gawlik, [et al.], M. Pluta, W. Suwała, A. Szurlej, A. Wyrwa, J. Zyśk, Coal for Polish energy sector in 2050 perspective - scenario analyses, Mining Chamber of Industry and Commerce, Wydawnictwo Instytutu Gospodarki Surowcami Mineralnymi i Energią PAN, Katowice, (2013), (in Polish)

11. A. Wyrwa, M. Pluta, S. Skoneczny, T. Mirowski, Modelling the mid-term development of an energy system with the use of a technology explicit partial equilibrium model, Escience on distributed computing infrastructure: PLGrid plus. Springer-Verlag GmbH, LNCS 8500; p. 489-503, (2014)

12. K. Badyda, G. M. Niewiński, A. Patrycy, W. Orzeszek, Próba oszacowania kosztów wdrożenia konkluzji BAT dla dużych źródet spalania, Nierówności Społeczne a Wzrost Gospodarczy, nr 46 (2/2016), (in Polish) 